\title{
Pengembangan dan Validasi Rancang Bangun Sistem Informasi Surat Elektronik Poliklinik Berbasis Website
}

Muttaqin Kholis Ali

Program Studi Pendidikan Teknologi dan Kejuruan, Fakultas Teknik, Universitas Negeri Padang, Indonesia

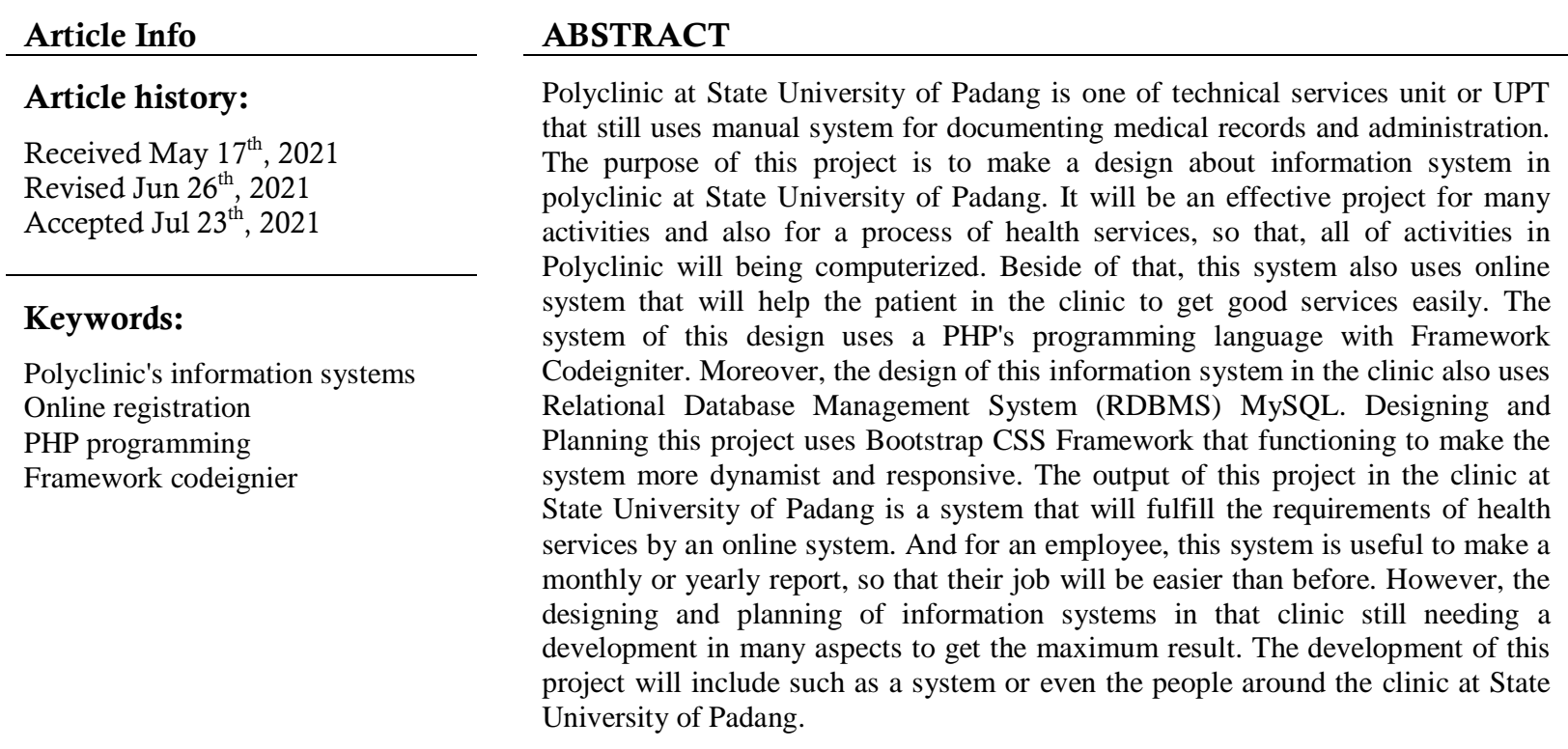

(C) 2021 The Authors. Published by IICET.

This is an open access article under the CC BY-NC-SA license (https://creativecommons.org/licenses/by-nc-sa/4.0)

Corresponding Author:

Ali, M. K.,

Program Studi Pendidikan Teknologi dan Kejuruan, Fakultas Teknik, Universitas Negeri Padang, Indonesia Email: muttaqinkholis51@gmail.com

\section{Pendahuluan}

Saat ini perkembangan teknologi infomasi semakin pesat disertai dengan berbagai jenis bentuk dan manfaatnya. Perkembangan ini tentu tidak terlepas dari kebutuhan untuk mendapatkan informasi yang cepat dan akurat. Salah satu teknologi yang dapat memenuhi hal tersebut adalah komputer. Dengan adanya teknologi komputer diharapkan akan diperoleh informasi yang lebih berkualitas. Perangkat komputer menjadi salah satu komponen penting untuk mendukung pekerjaan rutin para pemakainya. Poliklinik Universitas Negeri Padang melayani berbagai jenis pelayanan kesehatan. Mulai dari check up, pegobatan ringan, pengobatan sedang, mengeluarkan surat keterangan sehat dan jenis pelayanan lain yang berhubungan dengan kesehatan. Berdasarkan data 4 bulan terakhir yang tercatat dalam laporan bulanan Poliklinik Universitas Negeri Padang diatas menunjukkan adanya kenaikan jumlah pasien yang berobat di Poliklinik UNP. Hal ini tentu mengharuskan pelayanan yang lebih baik dan membutuhkan sistem yang lebih memadai untuk mengantisipasi terjadinya kesalahan yang diakibatkan kelalaian manusia. Untuk itu poliklinik UNP 
membutuhkan sistem informasi rekam medis yang dapat mengakomodir kebutuhan civitas akademik UNP akan layanan kesehatan yang cepat dan akurat.

\section{Sistem Informasi (Sistem Informasi)}

Menurut Jogiyanto (2005) sistem adalah bagian - bagian yang saling berkaitan erat dan membentuk suatu kesatuan yang saling berinteraksi antara satu bagian dengan bagian yang lainnya untuk mencapai suatu tujuan, artinya apabila salah satu bagian dari sistem tidak ada maka sistem tersebut tidak akan berjalan sebagaimana mestinya.

\section{Rekam Medis}

Dalam Peraturan Menteri Kesehatan No. 269/MenKes/PER/111/2008 tentang rekam medis, disebutkan pengertian rekam medis adalah berkas berisikan catatan dan dokumen tentang identitas pasien, pemeriksaan, pengobatan, tindakan dan pelayanan lain kepada pasien pada sarana pelayanan kesehatan.

\section{Pengolahan Data}

Pengolahan data (data processing) adalah manipulasi data kedalam bentuk yang lebih berarti berupa informasi, sedangkan informasi adalah hasil dari kegiatan-kegiatan pengolahan data yang memberikan bentuk yang lebih berarti dari suatu kegiatan atau peristiwa. Pada dasarnya sistem komputer memiliki beberapa fungsi melakukan pengolahan data, penyimpanan data, pemindahan data dan kendali.

\section{Flowmap}

Flowmap merupakan bagan yang menunjukkan arus pekerjaan secara keseluruhan dari sistem. Bagan ini menjelaskan urutan-urutan dari prosedur yang terdapat dalam sebuah sistem. Flowmap juga memberi gambaran bagaimana sistem yang akan kita bangun. Flowmap juga memberi pemahaman yang cukup bagi kita untuk mengambil keputusam apakah sistem yang sedang berjalan masih layak untuk dilanjutkan atau perlu pengembangan dan pembaharuan.

\section{Algoritma}

Menurut Rinaldi Munir (2007), algoritma yaitu urutan langkah-langkah logis untuk memecahkan masalah. Kata logis merupakan kata kunci dalam algoritma. Langkah-langkah dalam algoritma harus logis dan harus dapat ditentukan bernilai salah atau benar. Dalam beberapa konteks, algoritma adalah spesifikasi urutan langkah untuk melakukan pekerjaan tertentu.

\section{Entity Relationship Diagram (ERD)}

Diagram ER (Entity-Relationship) menurut Edhy Sutanta (2011:91) adalah model yang digunakan untuk menjelaskan hubungan antar data dalam basis data kepada pengguna secara logic. Entity Relationship diagram (ERD) merupakan teknik yang digunakan untuk memodelkan kebutuhan data dari suatu organisasi, biasanya oleh System Analys dalam tahap analisis persyaratan proyek pengembangan system.

\section{Data Flow Diagram (DFD)}

Data Flow Diagram (DFD) digunakan untuk memperjelas proses-proses yang terjadi dalam sistem. DFD memuat proses yang mentransformasi data, aliran data yang menggerakan data, objek yang memproduksi, serta data store yang menjadi tempat penyimpanan data.

\section{Context Diagram}

Diagram konteks adalah sistem yang digambarkan dengan sebuah proses, dan menunjukan semua entitas yang menerima informasi dari atau memberikan informasi ke sistem. Dapat dikatakan bahwasanya pada diagram konteks terdapat gambaran setiap proses dari masing-masing entitas baik yang menerima informasi dan atau memberikan infomrasi ke dalam sistem.

\section{Database}

Menurut Abdul Kadir (2003:254), Basis data (database) adalah suatu pengorganisasian sekumpulan data yang saling terkait sehingga memudahkan aktivitas untuk memperoleh informasi. Basis data dimaksudkan untuk mengatasi problem pada sistem yang memakai pendekatan berbasis berkas.

\section{HTML 5}

Menurut Priyanto dan Jauhari (2014 : 13) "Hypertext Markup Language (HTML) adalah Bahasa standar yang digunakan untuk menampilkan halaman web". HTML5 adalah revisi kelima dari HTML. Tujuan utama pengembangan HTML5 adalah untuk memperbaiki teknologi HTML agar mendukung teknologi multimedia terbaru, mudah dibaca oleh manusia dan juga mudah dimengerti oleh mesin.

\section{PHP}

Menurut dokumen resmi PHP merupakan singkatan dari PHP Hypertext Preprocessor. Merupakan bahasa berbentuk skrip yang ditempatkan dalam server. Hasilnyalah yang dikirimkan ke klien, tempat pemakai 
menggunakan browser. Secara khusus, PHP dirancang untuk membentuk aplikasi web dinamis. Artinya dapat membentuk suatu tampilan berdasarkan permintaan terkini.

\section{MySQL}

MySQL adalah database server relasional yang gratis dibawah lisensi General Public License (GNU). Dengan sifatnya yang open source, memungkinkan user untuk melakukan modifikasi pada source code-nya untuk memenuhi kebutuhan spesifik mereka sendiri. MySQL adalah sebuah DBMS Relasional yang menyimpan data dalam tabel terpisah.

\section{Analisis dan Perancangan Sistem}

\section{Analisis Dokumen}

Dokumen yang digunakan dalam sistem ini dapat berupa dokumen input dan output. Dokumen input merupakan bentukan rancangan aktif antara user dengan komputer, tujuannya adalah untuk menjamin pemasukan data dapat dimengerti oleh si pemakai sistem, sehingga dapat menciptakan keakuratan dalam pengenterian data dan efisien terhadap waktu. Sedangkan dokumen output merupakan seluruh form yang disediakan dalam sistem yang memuat informasi dari hasil data yang diinputkan kedalam sistem serta informasi yang dikirim ke user.

Data penduduk didapatkan dari hasil pencatatan KASI Pemerintahan dan Pelayanan Umum ketika penduduk terdaftar sebagai Warga Negara Indonesia. Untuk mencari kembali suatu data, maka Bagian Sesi Pemerintahan kembali membuka buku tersebut dan kemudian mencarinya secara manual. Begitu juga dalam pembuatan laporan akhir, Bagian Sesi Pemerintahan kembali membuka buku tersebut untuk mendapatkan bahan penyusunan laporan.

Data kelahiran didapatkan saat penduduk tersebut lahir. Untuk mencari kembali suatu data, maka Bagian Sesi Pemerintahan kembali membuka buku tersebut dan kemudian mencarinya secara manual. Begitu juga dalam pembuatan laporan akhir, Bagian Sesi Pemerintahan kembali membuka buku tersebut untuk mendapatkan bahan penyusunan laporan.

Data kematian didapatkan saat penduduk tersebut meninggal dunia. Untuk mencari kembali suatu data, maka Bagian Sesi Pemerintahan kembali membuka buku tersebut dan kemudian mencarinya secara manual. Begitu juga dalam pembuatan laporan akhir, Bagian Sesi Pemerintahan kembali membuka buku tersebut untuk mendapatkan bahan penyusunan laporan. Proses ini berlaku baik pada akhir periode, Bagian Sesi Pemerintahan akan mengirimkan datanya (berupa catatan di buku dan lembaran arsip) kepada Camat, guna pembuatan laporan.

Permasalahan yang ada dalam proses diatas, tentunya tidak jauh dari ketidakefisienan waktu dan tenaga. Proses pencarian kembali data memerlukan waktu lama, karena harus cari satu per-satu, demikian juga dalam pembuatan laporan. Pertukaran data antara Bagian Sesi Pemerintahan-pun tidak bisa dilakukan dengan segera, harus menunggu data yang datang secara manual, yakni dibawa oleh orang (staff). Masalah keamanan data pun perlu diperhatikan. Pencatatan data pada media kertas saja sangat rentan untuk hilang dan rusak. Berbagai tindak kejahatan dan bencana alam dapat menyebabkan itu semua. Proses backup data sampai saat ini tidak dilakukan. Hal tersebut dapat dimaklumi karena akan sangat melelahkan untuk membuat salinan dari suatu buku ke buku lainnya secara manual.

\section{Analisis sistem yang akan dikembangkan Analisis User}

Tabel $1<$ Perincian User $>$

User Peran

Pasien Merupakan user yang memiliki hak akses untuk melihat daftar-daftar dokter yang melakukan praktek. Users harus mendaftarkan diri dan mengisi format pendaftaran untuk mendapatkan layanan dari Sistem Informasi ini. Users jga dapat melihat hasil rekam medis dari konsultasi yang telah dijalani. Pasien merupakan civitas akademik UNP dan masyarakat umum.

Admin Merupakan user yang memiliki wewenang untuk me-insert, update, delete segala sesuatu yang terdapat dalam system informasi serta berperan sebagai user yang memanage sistem.

Dokter Merupakan user yang memiliki hak akss untuk melihat daftar pasien yang berkonsultasi, serta dapat mengisikn data rekam medis pasien, serta dapat mencetak resep obat yang akan diberikan kepada pasien. 


\begin{tabular}{lc}
\hline \multicolumn{1}{c}{ User } & Peran \\
\hline Perawat & Merupakan user yang memiliki hak akses atas laporan data pasien dan laporan jumlah pasien \\
& yang melakukan pendaftaran konsultasi setiap harinya, \\
Pegawai & Merupakan user yang melakukan urusan administrasi pada layanan kesehatan di Poliklinik \\
Poliklinik & Universitas Negeri Padang. \\
\hline
\end{tabular}

Analisis Dokumen

\begin{tabular}{|c|c|}
\hline Dokumen Input & Keterangan \\
\hline Data Pasien & $\begin{array}{l}\text { Data pasien yang dimasukkan mencakup data rekam medis, nama } \\
\text { pasien, jenis kelamin, tanggal lahir, tempat lahir, alamat dan telepon }\end{array}$ \\
\hline Data Dokter & $\begin{array}{l}\text { Data dokter yang dientrikan sesuai dengan kebutuhan sistem. Adapun } \\
\text { data dokter yang diinputkan adalah id dokter, nama dokter, spesialis, } \\
\text { alamat dan nomor telepon dokter. }\end{array}$ \\
\hline Data Obat & $\begin{array}{l}\text { Data obat yang dimasukkan mencakup data kode obat, nama obat, } \\
\text { kemasan, jumlah satuan, satuan dan harga. }\end{array}$ \\
\hline Data Pegawai Poliklinik & $\begin{array}{c}\text { Data pegawai yang dimasukkan mencakup data Id pegawai, nama } \\
\text { perawat, jenis kelamin, tanggal lahir, tempat lahir, alamat dan nomor } \\
\text { telepon. }\end{array}$ \\
\hline Data Perawat & $\begin{array}{c}\text { Data perawat yang dimasukkan mencakup data Id perawat, nama } \\
\text { perawat, jenis kelamin, tanggal lahir, tempat lahir, alamat dan nomor } \\
\text { telepon. }\end{array}$ \\
\hline Data Resep Obat & $\begin{array}{l}\text { Data yang diinputkan ini mencakup nomor rekam medis, nomor resep, } \\
\text { tanggal resep dan Id dokter. Tanggal resep menggunakan penanggalan } \\
\text { sesuai kebutuhan user. }\end{array}$ \\
\hline Data Fakultas & $\begin{array}{l}\text { Data Fakultas berisi semua nama fakultas yang ada di Universitas Negeri } \\
\text { Padang. Data fakultas juga memberi informasi mengenai fakultas pasien } \\
\text { yang berobat ke Poliklinik Universitas Negeri Padang }\end{array}$ \\
\hline Data Rekam Medis & $\begin{array}{c}\text { Data rekam medis yang dimasukkan mencakup data nama pasien, } \\
\text { nomor rekam medis, tanggal kunjungan, keluhan utama, riwayat } \\
\text { penyakit terdahulu, riwayat penyakit keluarga, hasi diagnosa dokter dan } \\
\text { anamnesis. }\end{array}$ \\
\hline
\end{tabular}

Tabel $3<$ Dokumen Output $>$

\begin{tabular}{lc}
\hline \multicolumn{1}{c}{ Dokumen } & Keterangan \\
Data Rekam Medis & $\begin{array}{c}\text { Pada bagian atas rekam medis ini dapat dilihat nama pasien, nomor rekam medis, } \\
\text { tanggal cetak serta identitas Poliklinik. Rekam medis ini mencakup tanggal } \\
\text { kunjungan pasien, anamnesis, keluhan utama, riwayat penyakit dahulu, riwayat } \\
\text { penyakit keluarga dan diagnosa dokter. Desain output ini sebagai acuan bagi } \\
\text { pegawai Poliklinik dalam pembaharuan data pasien dan sebagai acuan untuk dokter } \\
\text { memberi diagnosis dan anamnesis untuk pasien. }\end{array}$ \\
$\begin{array}{l}\text { Kartu berobat ini diberikan pada setiap pasien baru atau pasien lama yang } \\
\text { Kartu Berobat } \\
\text { kehilangan kartu berobat. Kartu berobat ini menjadi penyambung antara pihak } \\
\text { poliklinik dengan pasien. Kartu berobat ini mencakup nomor rekam medis, nama } \\
\text { pasien dan alamat pasien }\end{array}$ \\
$\begin{array}{l}\text { Laporan Bulanan } \\
\text { Rekam Medis } \\
\text { Laporan Bulanan } \\
\text { Penyakit }\end{array}$ \\
$\begin{array}{c}\text { Laporan bulanan rekam medis ini memberi informasi mengenai pasien yang datang } \\
\text { berobat dan sudah mendapat penanganan dari Poliklinik Universitas Negeri Padang. }\end{array}$ \\
Laporan bulanan penyakit berisi 10 penyakit terbanyak yang diderita pasien \\
Poliklinik Universitas Negeri Padang. Dalam laporan ini akan dirunut jumlah \\
penderita penyakit yang terbanyak dalam satu bulan kerja Poliklinik Universitas \\
$\begin{array}{c}\text { Negeri Padang. } \\
\text { Penderita Penyakit } \\
\text { Laporan Rekap }\end{array}$ \\
$\begin{array}{c}\text { Tahunan } \\
\text { Laporan bulanan penyakit menunjukkan semua penyakit berdasarkan data ICD 10 } \\
\text { dan menghitung jumlah penderita penyakit tiap bulannya. }\end{array}$ \\
\hline
\end{tabular}


Context Diagram

Diagram konteks (Context diagram) merupakan tingkatan tertinggi dalam diagram alir data dan hanya memuat proses, menunjukkan sistem secara keseluruhan. Diagram konteks dari Sistem Informasi Kependudukan dapat digambarkan sebagai berikut :

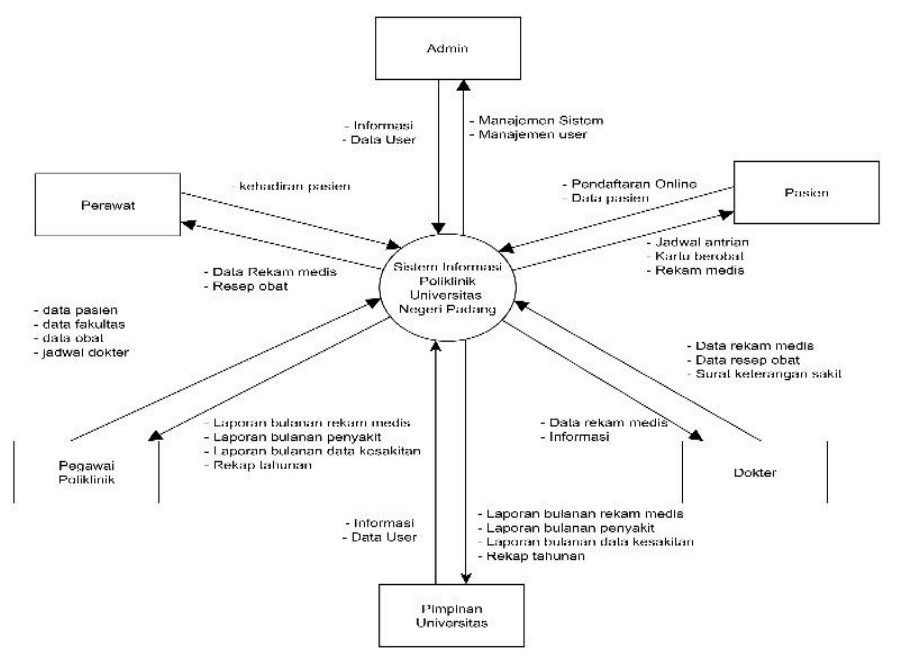

Gambar $1<$ Context Diagram Sistem Informasi Poliklinik UNP>

Use case Diagram

Use Case Diagram merupakan pemodelan untuk kelakukan (behavior) sistem informasi yang akan dibuat. Diagram use case mendeskripsikan sebuah interaksi antara satu atau lebih aktor dengan sistem informasi yang akan dibuat. Diagram use case digunakan untuk mengetahui fungsi apa saja yang ada didalam sebuah sistem informasi dan siapa saja yang berhak menggunakan fungsi-fungsi tersebut. Fasilitas yang disediakan oleh sistem kepada user dapat dilihat dari perancangan use case diagram berikut :

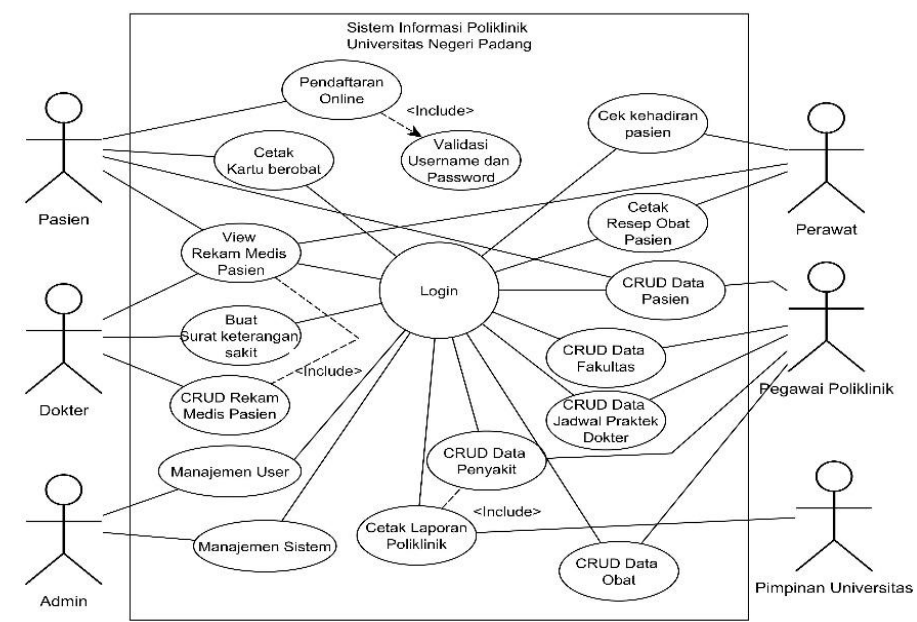

\section{Gambar 2 <Use Case Diagram Sistem Informasi Poliklinik UNP>}

Pasien setelah melakukan login akan mendapatkan hak akses untuk melihat data rekam medisnya. Pegawai poliklinik, stelah melakukan login, maka user ini berhak mendapatkan data pasien, melakukan pencetakan laporan kunjungan bulanan, kunjungan harian, pendapatan bulanan dan pendapatan harian. Dokter setelah melakukan login dapat melihat data pasien dan menginputkan data rekam medis pasien yang melakukan konsultasi dengan dokter yang bersangkutan dan dapat mencetak data resep. Pimpinan UNP setelah melakukan login dapat memeriksa laporan kunjungan dan pendapatan. Admin setelah melakukan login dapat melakukan manajerial terhadap data user dan juga sistem.

\section{Actifity Diagram}

Diagram aktifitas menunjukan aktifitas sistem dalam bentuk kumpulan aksi-aksi serta juga menggambarkan hak apa saja yang dimiliki oleh seorang user terhadap system. 
1. Actifity Diagram Login

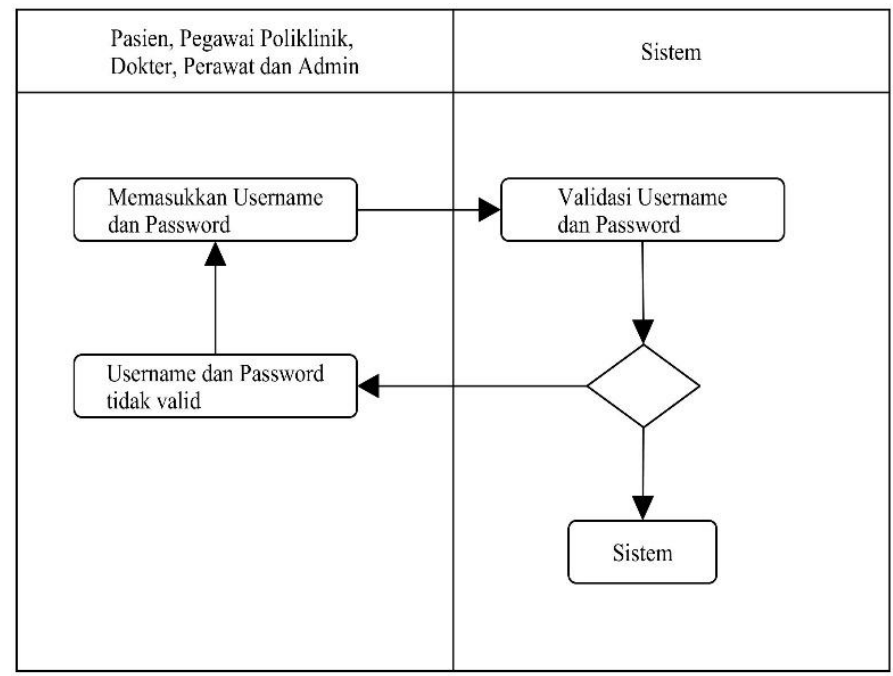

Gambar 3 <Activity Diagram Login>

Activity diagram login menampilkan aktifitas login dimulai dengan memasukkan username dan password oleh user, username dan password tersebut akan di cek validitas oleh sistem, jika valid maka proses bisa dilanjutkan sedangkan jika tidak valid maka sistem akan meinta user untuk memasukkan kembali username dan password.

2. Actifity Diagram Pasien

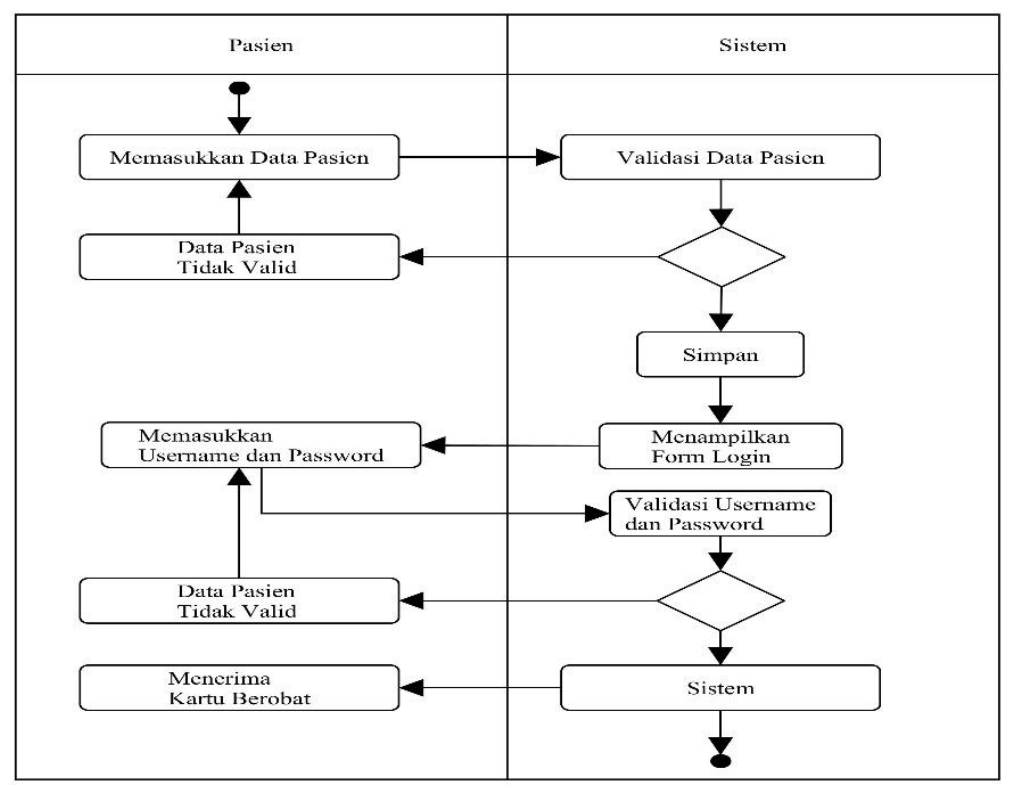

Gambar 4 <Activity Diagram Pasien>

Aktifitas pendaftaran pasien di klinik menggambarkan kejadian pada saat calon pasein melakukan pendaftaran. Pasien akan mendaftar untuk mengambil nomor pendaftaran dari sistem. Pesan kepada sistem dengan berisi data pasien itu sendiri termasuk status apakah pasien berasal dari civitas akademik UNP atau umum. Kemudian sistem akan memeriksa data pasien tersebut, Jika telah sesuai maka pasien akan menerima balasan dari sistem berisikan nomor antrian. 
3. Actifity Diagram Daftar Antrian

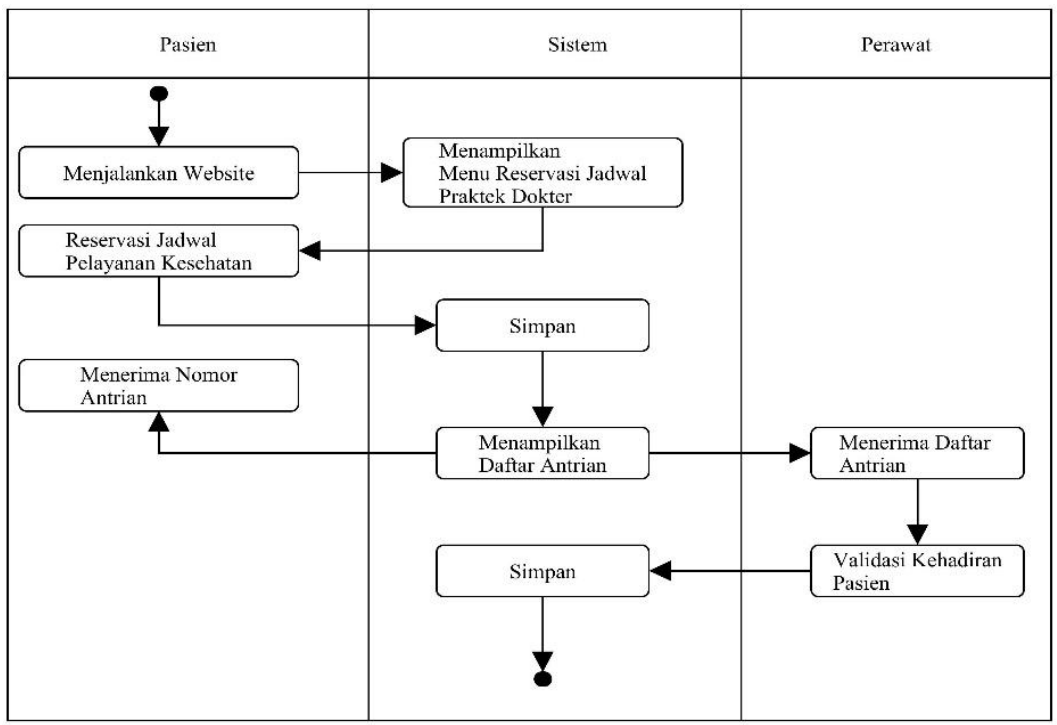

Gambar 5 <Activity Diagram Daftar Antrian>

Activity Diagram daftar antrian merupakan penngelolaan daftar antrian pasien yang akan dilakukan pada Klinik pada hari tersebut. Pegawai poliklinik akan login ke website kemudian website akan menampilkan menu utama, setelah itu Pegawai poliklinik akan memilih menu daftar antrian. Maka akan terlihat daftara antrian pasien pada hari tertentu, dan Pegawai poliklinik mencetak daftar antrian.

4. Actifity Diagram Rekam Medis

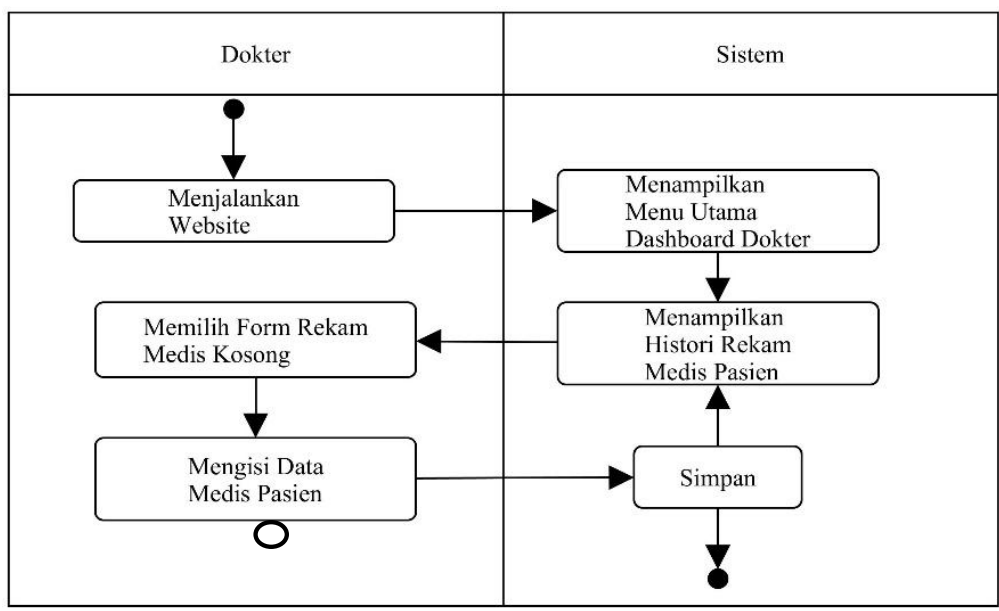

\section{Gambar 6 <Activity Diagram Rekam Medis>}

Gambar di atas menjelaskan bahwa, data hasil konsultasi pasien dengan dokter akan disimpan pada sistem, dan yang akan menginputkan data yaitu dokter sendiri atau bisa dibantu Pegawai poliklinik. Dokter akan masuk ke sistem, kemudian akan memilih menu Rekam Medis, kemudian akan mengisikan hasil konsulttasi pasien dengan dokter dan akan menyimpan pada database.

\section{Class Diagram}

Class Diagram menggambarkan struktur sistem dari segi pendefenisisan kelas-kelas yang akan dibuat untuk membangun sistem. Elemen-eleman class diagram dalam pemodelan UML terdiri dari: Class-class, struktur class, sifat class (class behavior), perkumpulan/gabungan (association), pengumpulan/kesatuan (agregation), 
ketergantungan (dependency), relasi-relasi turunannya, keberagaman dan indikator navigasi, dan role name (peranan/tugas nama).

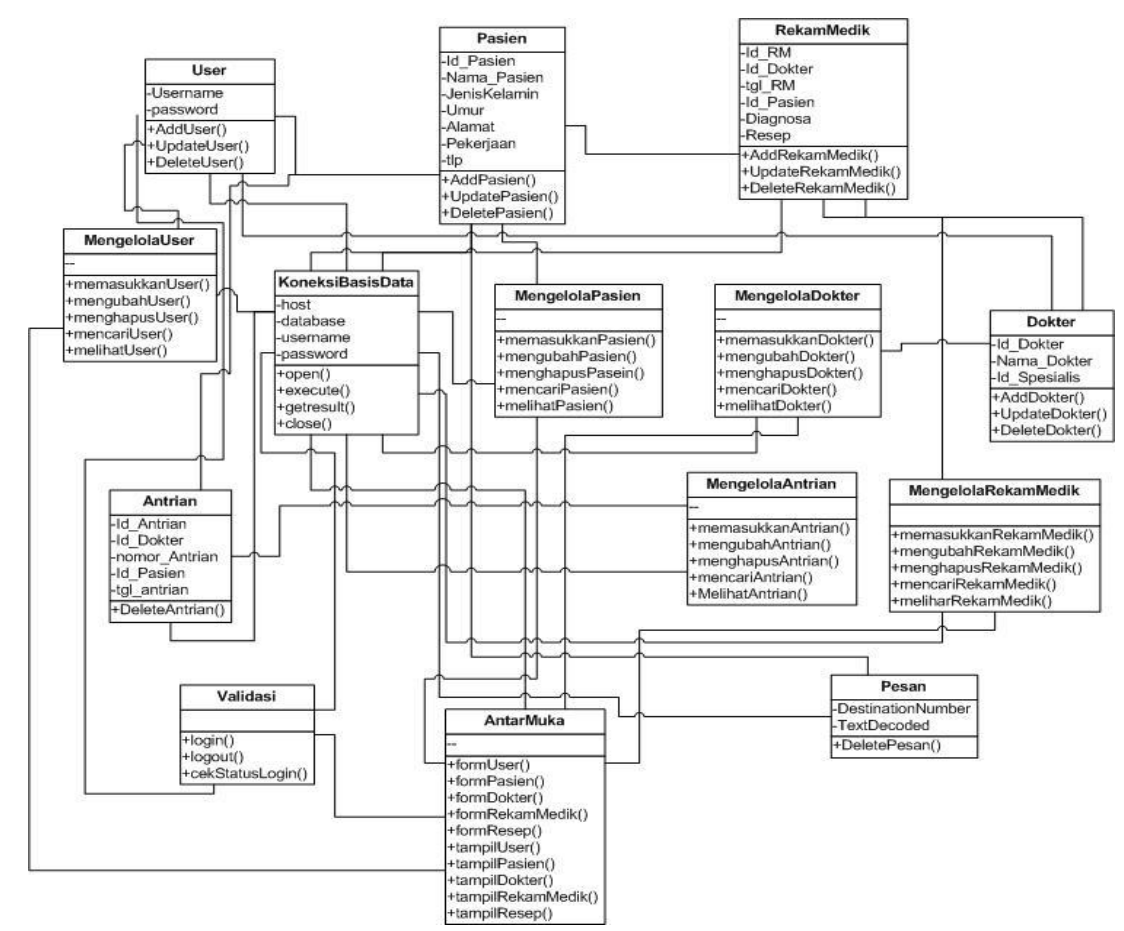

Gambar 7 < Class Diagram Sistem Informasi Poliklinik UNP>

\section{Hasil dan Pembahasan}

Hasil rancangan merupakan tahap uji coba terhadap Sistem Informasi Poliklinik Universitas Negeri Padang yang telah dirancang, apakah sudah dapat berjalan dengan benar atau tidak. Berdasarkan analisis yang telah dilakukan sebelumnya terhadap Sistem Informasi Poliklinik Universitas Negeri Padang.

\section{Halaman Pengunjung}

Halaman ini merupakan halaman utama yang ditemui oleh setiap user ketika membuka halaman website Sistem Informasi Poliklinik Universitas Negeri Padang. Pada bagian header terdapat beberapa menu, diantaranya: Beranda, Tentang, Pelayanan, Masuk/Daftar dan Kontak. Pada bagian footer terdapat contact person pelayanan ambulance dan akun sosial media yang dimiliki oleh klinik.

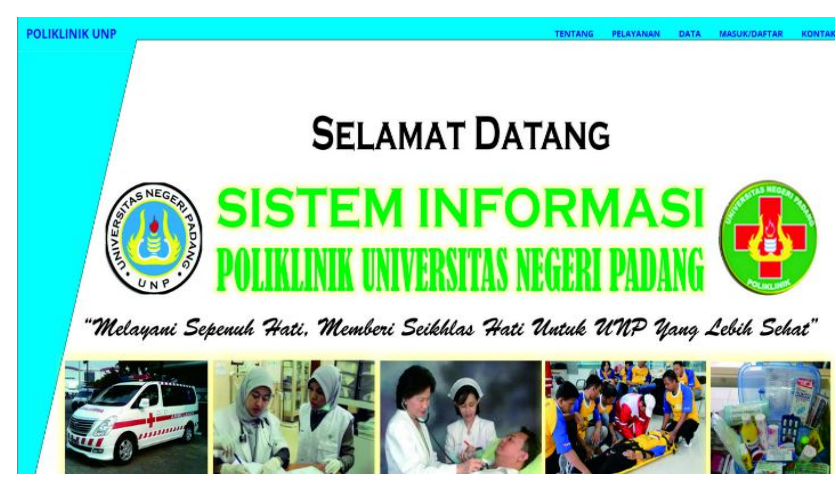

Halaman Registrasi

Gambar 9 <Halaman Beranda $>$

Halaman Registrasi merupakan halaman yang akan dilakukan oleh para perantauan. Hal yang harus diinputkan berupa : No Kartu Keluarga, nama, alamat, no KTP, tempat lahir, tanggal lahir, jenis kelamin, agama, status perkawinan, no telepon, email, username dan password. Username dan Password ini agar bisa 
masuk ke menu user penduduk agar dapat mengajukan surat permohonan dan mencetak surat permohonan. Berikut adalah halaman tampilan registrasi penduduk di Kenagarian Saniangbaka, Kab. Solok:

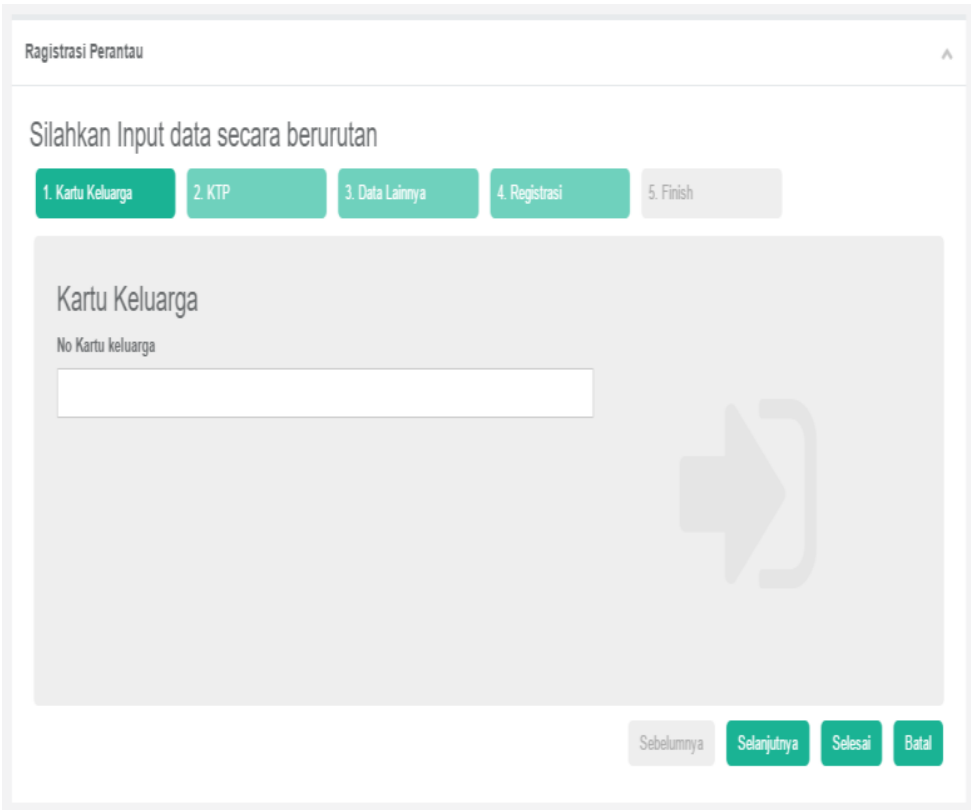

\section{Gambar $10<$ Halaman Registrasi $>$}

Gambar di atas merupakan tampilan halaman registrasi untuk para perantau yang ingin mengajukan surat permohonan dengan jenis layanan yang ada pada sistem kependudukan di Kenagarian Saniangbaka, Kab. Solok.

\section{Halaman Login}

Halaman login ini berfungsi sebagai pintu gerbang untuk bisa masuk kedalam sistem secara keseluruhan terhadap semua level akses user. Halaman login dari sistem informasi kependudukan di kenagarian saniangbaka terdiri dari Label SIK (Sistem Informasi Kependudukan), form inputan username, form inputan password dan button action login. Berikut tampilan halaman login Sistem Informasi Kependudukan di Kenagarian Saniangbaka, Kab. Solok:

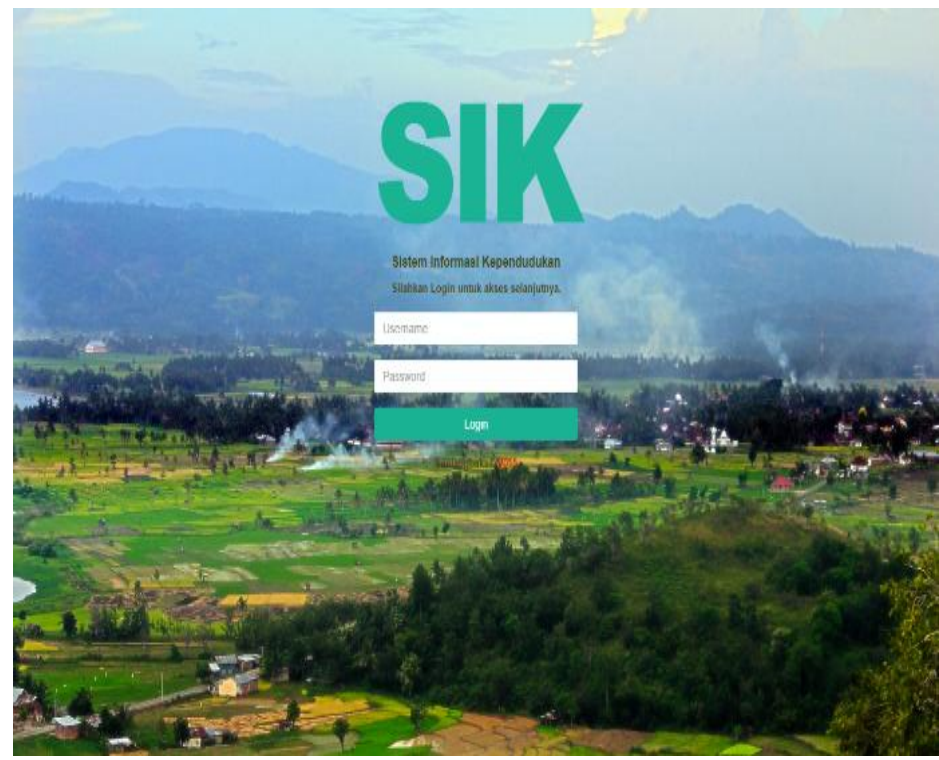

\section{Gambar <Halaman Login $>$}




\section{Halaman Permohonan}

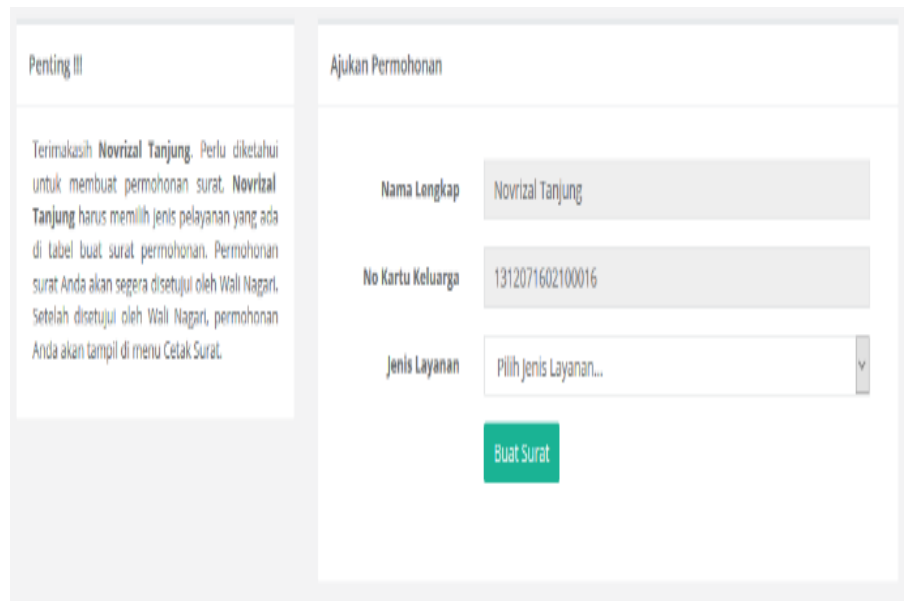

Gambar 12. Halaman Permohonan>

Gambar di atas merupakan halaman view permohonan penduduk yang dilakukan oleh penduduk Nagari Saniangbaka. Setelah membuat surat permohonan maka aka ada lagi proses untuk mengisi form surat permohonan yang sesuai dengan jenis layanan yang dipilih sebelumnya.

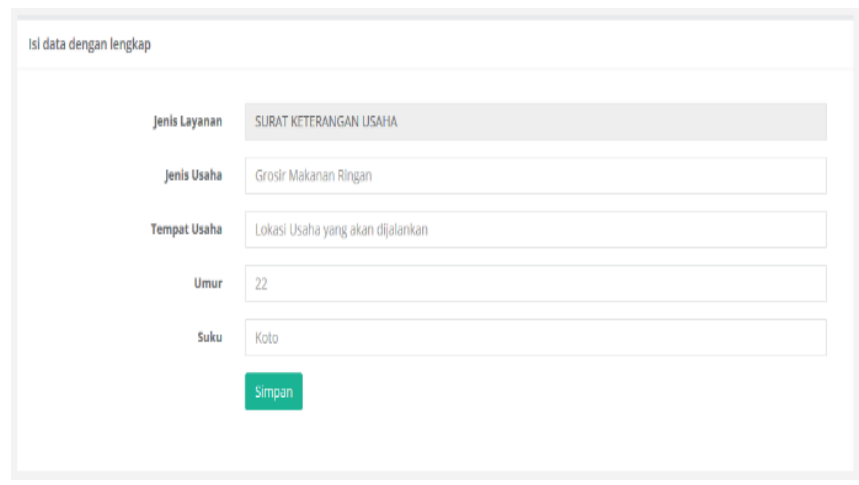

Gambar $13<$ Form Input Permohonan $>$

Gambar di atas merupakan halaman form permohonan yang sesuai dengan jenis layanan yang dipilih. Gambar diatas adalah form permohonan surat keterangan usaha dari salah satu 16 jenis layanan kependudukan di Kenagarian Saniangbaka.

\section{Halaman Status Permohonan}

Surat permohonan penduduk merupakan suatu adminstrasi kependudukan yang dilakukan secara online, penduduk menunggu persetujuan oleh operator dan walinagari agar dapat mencetak surat permohonan penduduk.

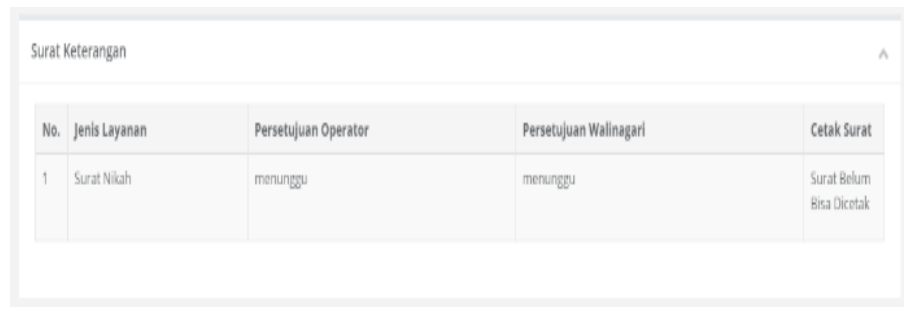

Gambar 14 <Status Permohonan> 
Gambar di atas adalah Status Permohonan yang belum disetujui oleh Operator dan Pimpinan Nagari Saniangbaka / Walinagari.

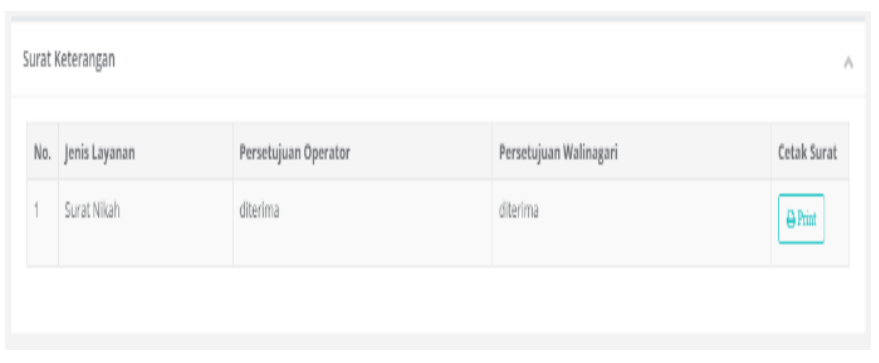

Gambar $15<$ Status Permohanan $>$

Gambar di atas merupakan Status Permohonan penduduk yang telah disetujui oleh Operator dan Pimpinan, setelah disetujui oleh kedua pihak maka penduduk dapat mencetak bukti surat keterangan permohonan penduduk.

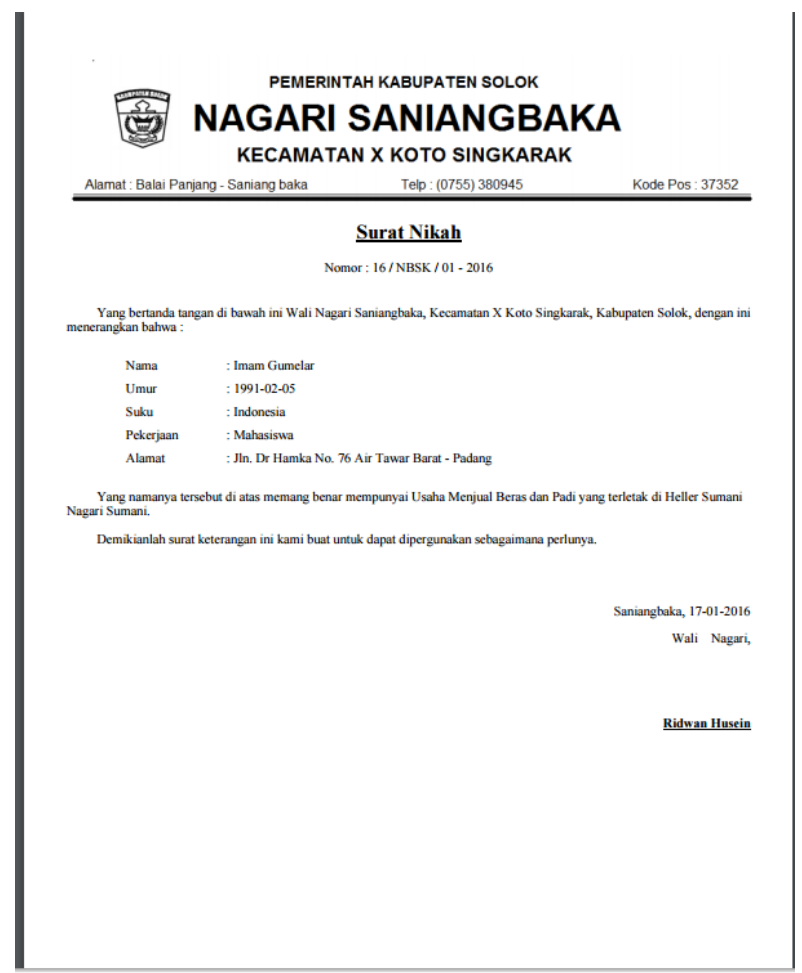

Gambar $12<$ Cetak Surat Permohonan>

\section{Simpulan}

Berdasarkan tujuan Pengembangan Portal Nagari Berbasis Communtity-Based Government Menggunakan model MVC maka dapat disimpulkan sebagai berikut: 1) Pengembangan sistem permohonansurat yang mudah, cepat dan tepat dalam pemakaian efisensi waktu yang dipakai selama proses dan prosedur berjalan dan mengurangi pemakaian kertas. 2) Pengembangan sistem informasi kependudukan yang bisa diakses secara online. 3) Pengembangan sistem yang multi platform yang tak terbatas dengan media aksesdan perangkatnya. 4) Sistem Informasi ini dikembangkan dengan menggunakan bahasa pemograman PHP dengan memanfaatkan framework CodeIgniter 3.0.3. dan menggunakan bahasa pemograman web lainnya seperti HTML, CSS, dan JavaScript dan menggunakan MySQL sebagai database server.. 


\section{Referensi}

KadirAbdul. (2003). Pengenalan Sistem Informasi. Yogyakarta: Andi.

Betha Sidik, Ir dan husni iskandar pohan. (2012). Pemograman Web Dengan HTML. Bandung.Informatika.

Budi Dharma Oetomo, S.kom,MM. (2002). Perencanaan \& Pembangunan Sistem Informasi. Yogyakarta.Penerbit Andi.

Fathansyah,Ir. (1999). Basis Data. Bandung: Penerbit Infomatika.

Sari,YR. (2012). Perancangan Sistem Administrasi Kependudukan di Desa Trihanggo Kecamatan Gamping KabupatenSlemen.

http://repository.amikom.ac.id/index.php/detail/2816/perancangan\%20sistem\%20administrasi\%20ke pendudukan\%20di\%20desa\%20trihanggo\%20kecamatan\%20gamping\%20kabupaten\%20slemen.

Sukapti, (2012). Analisis dan Perancangan Sistem Administrasi Kependudukan pada Kantor Kelurahan Desa Banyuroto Dengan Menggunakan Visual Basic 6.0dan SQL Server 2000. http://repository.amikom.ac.id/files/Naskah_Publikasi\%2005.11.0920.pdf

Hanif Al Fatta. (2007).Analisis dan perancangan sistem informasi untuk keunggulan bersaing perusahaan dan organisasi modern. Yogyakarta: Andi.

Jasmadi dan E-Media Solusindo. (2008).Membangun Komunitas Online Praktis. Jakarta:Elex Media Komputindo.

Miftahul Huda dan Bunafit Komputer. (2010). Membuat Aplikasi Databasedengan Java, MySQL dan Netbeans.Jakarta.PT Elex Media Komputindo.

Prabowo Pudjo Widodo dan Herlawati. (2011). Menggunakan UML. Bandung : Informatika.

Rudy Tantra. (2012). Manajemen Proyek Sistem Informasi. Yogyakarta. Penerbit Andi.

Tata Sutabri, S.Kom, MM, (2005). Sistem Informasi Manajemen. Yogyakarta: Penerbit Andi

Wardana. (2010). Menjadi Master PHP dengan Framework Codeigniter. Jakarta: Elex Media Komputindo.

Yakub. (2012). Pengantar Sistem Informasi. Yogyakarta.Graha Ilmu.

ZulkifliAmsyah, MLS, Drs. (2003). Manajemen Sistem Informasi. Jakarta:PT Gramedia Pustaka Utama. 